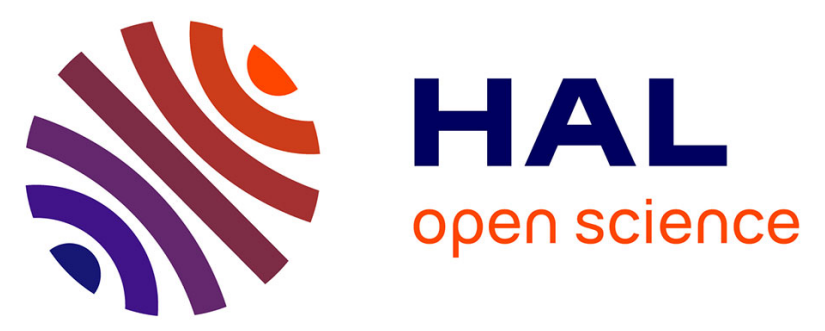

\title{
The effect of MM polarization on the QM/MM transition state stabilization: application to chorismate mutase
}

Christopher Reynolds, Christopher J Illingworth, Kevin E Parkes, Chris R Snell, Vicent Moliner, Sergio Marti

\section{To cite this version:}

Christopher Reynolds, Christopher J Illingworth, Kevin E Parkes, Chris R Snell, Vicent Moliner, et al.. The effect of MM polarization on the QM/MM transition state stabilization: application to chorismate mutase. Molecular Physics, 2008, 106 (12-13), pp.1511-1515. 10.1080/00268970802077850 . hal00513198

\section{HAL Id: hal-00513198 \\ https://hal.science/hal-00513198}

Submitted on 1 Sep 2010

HAL is a multi-disciplinary open access archive for the deposit and dissemination of scientific research documents, whether they are published or not. The documents may come from teaching and research institutions in France or abroad, or from public or private research centers.
L'archive ouverte pluridisciplinaire HAL, est destinée au dépôt et à la diffusion de documents scientifiques de niveau recherche, publiés ou non, émanant des établissements d'enseignement et de recherche français ou étrangers, des laboratoires publics ou privés. 


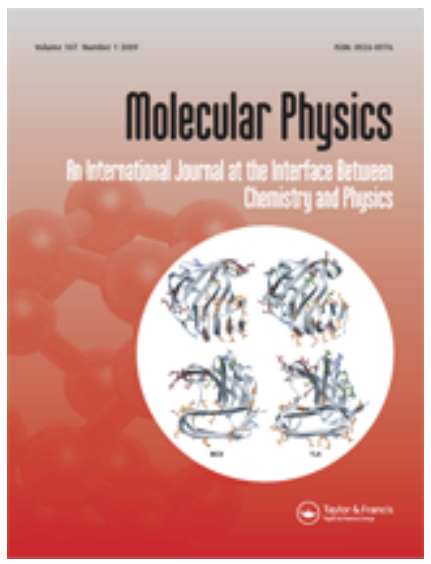

\section{The effect of MM polarization on the QM/MM transition state stabilization: application to chorismate mutase}

\begin{tabular}{|r|l|}
\hline Journal: & Molecular Physics \\
\hline Manuscript ID: & TMPH-2007-0385.R1 \\
\hline Manuscript Type: & Full Paper \\
\hline Author: & 19-Mar-2008 \\
\hline & $\begin{array}{l}\text { Complete List of Authors: } \\
\text { Reynolds, Christopher; University of Essex, Biological Sciences } \\
\text { Illingworth, Christophin; Medivir (UK) University of Essex, Biological Sciences } \\
\text { Marti, Sergio; Universitat Unitaume I }\end{array}$ \\
\hline \hline Keywords: & $\begin{array}{l}\text { QM/MM, polarization, Chorismate mutase, transition state } \\
\text { stabilization, induced charge }\end{array}$ \\
\hline
\end{tabular}

\section{scholarONE" \\ Manuscript Central}




\title{
The effect of MM polarization on the QM/MM
}

\section{transition state stabilization: application to}

\section{chorismate mutase}

\author{
C.J. R. ILLINGWORTH ${ }^{1}$, K. E. PARKES ${ }^{2}$, C. R. SNELL ${ }^{2}$, S. MARTI ${ }^{3}$, V. \\ MOLINER $^{3}$, C. A. REYNOLDS ${ }^{1, *}$ \\ ${ }^{1}$ Department of Biological Sciences, University of Essex, Wivenhoe Park, \\ Colchester, CO4 3SQ, United Kingdom \\ ${ }^{2}$ Medivir UK Ltd., Chesterford Research Park, Little Chesterford, Essex CB10 1XL, \\ United Kingdom \\ ${ }^{3}$ Departament de Quimica Fisica i Analitica, Universitat Jaume I, Box 224, Castellón, \\ Spain.
}


Hybrid quantum mechanics / molecular mechanics (QM/MM) calculations provide a mechanism for studying enzyme catalysed reactions at the molecular level. Here, through applications on the chorismate to prephenate rearrangement within the enzyme chorismate mutase, we have demonstrated the feasibility of including MM polarization into these calculations using the method of induced charges. MM polarization is shown to be a shortrange effect, such that $80 \%$ of the energy of MM polarization occurs within a $5 \AA$ residuebased cut-off of the substrate. MM polarization was shown to have a greater magnitude within the enzyme catalysed reaction than in the aqueous reaction, indicating that MM polarization may in principle have a significant effect on enzyme rate enhancement and mechanism. In both the enzyme and the aqueous case, the percentage contribution of MM polarization to the total stabilization energy was towards the upper end of the expected value. For the specific structures studied here, MM polarization lowered the energy barrier for the aqueous reaction, but the calculated contribution of MM polarization to both the reactant and transition structure stability were similar.

Keywords: QM/MM, induced charge, polarization, chorismate mutase, transition state stabilization 
For particular reactions, the origin of enzyme rate enhancement may still be a matter of debate, and this is the case for the Claisen rearrangement of chorismate to prephanate. This reaction within the enzyme chorismate mutase has become the focus of a large number of hybrid quantum mechanical/molecular mechanics (QM/MM) computational studies, partly as an exemplar system for methodology development, because the reaction does not involve any covalent bonding between the enzyme and the substrate, thus avoiding the difficult issue of link atoms. Moreover, the mechanism is believed to occur with the same mechanism in solution, and as such the enzyme has played a central role in recent debates about theories of enzyme catalysis. Here we propose to investigate whether MM polarization, which is currently ignored in most $\mathrm{QM} / \mathrm{MM}$ studies, can play a role in transition state stabilization.

Early studies of the system indicated, in line with the ideas of Pauling [1,9], that the catalysis proceeds by a mechanism of transition state stabilisation [10-12], in which the transition state is bound more strongly by the enzyme than the chorismate reactant. More recent controversy has focused around the argument that catalysis is instead due to the preferential binding by the enzyme of a reactive conformation of chorismate, known as a near-attack conformation.[13-15] Through improved computational techniques, more accurate simulations of the Claisen rearrangement have been carried out [16-18], leading to estimates 
of the reaction energy barriers that are in close correspondence with experimentally derived values $[16,19]$, and seeming to confirm the importance of transition state stabilisation. However, in these models electronic polarization is included in the QM model of the ligand but it is not incorporated into the MM model of the enzyme. Noting the importance of electrostatic effects in this system, [16,20] here we apply the method of induced charges [8,21-23] (IC) to incorporate polarization into a QM/MM(IC) model of the chorismate mutase reaction, with the aim of demonstrating the feasibility of studying the effect of enzyme polarization on transition state stabilization.

\section{Methods}

Calculations were performed on reactant, product, and transition state structures of Bacillus subtilis chorismate mutase (BsCM), and of the ligand in aqueous solution, taken from the $\mathrm{OH}_{\text {in }}$ pathway calculated by Marti et al. [24]. In each case, the QM region was defined to be the substrate. The enzymatic system was modelled using an MM region consisting of all residues with at least one atom within $10 \AA$ of the substrate, in at least one of the three structures, making a total of $1438 \mathrm{MM}$ points in each case. The aqueous solvent was modelled using an MM region with a cut-off chosen to include the 364 water molecules closest to the substrate, this being equivalent to a $10 \AA$ cut-off in the reactant system. This MM region is smaller than in other models of this system. In order to verify that this was sufficient to capture the effects of polarization in the MM region, a series of calculations were carried out measuring the MM polarization in the aqueous reactant system with cut-offs varying from 3 to $11 \AA$, which were extrapolated to give an estimate of the total MM polarization in an aqueous solvent with no cut-off.

Initial charges for residues in the MM region were derived from the Amber03 [25] forcefield. Gaussian03 [26] was used to carry out a QM optimisation on a water monomer at the 
B3LYP/6-31G(d) level of theory [27,28], and Stone's GDMA 1.3 program [29] was used to convert the charge distribution into a multipole series, which was then converted into potential derived point charges using the mulfit methodology $[21,22,30-32]$. Both the protein and the water charges are derived from correlated wavefunctions and therefore suitable for polarization calculations [32]. These are potential derived charges in which the potential is determined from a distributed multipole analysis up to hexadecapole in a spherical shell around the multipole centre. The optimal charges that reproduce this potential on the multipole centre and the atoms bonded to it are determined using an analytical procedure that avoids the use of a numerical grid [30].

For each QM/MM system, the wavefunction was calculated using Gaussian03 [26] and expressed as a distributed multipole analysis using GDMA 1.3 [29]. The field was then calculated at the MM (enzyme and/or water) atoms from the multipole series using ORIENT 4.5 [33]. Induced dipoles, $\underline{\mu}$, were calculated for each atom in the MM region, according to the equation

$\underline{\mu}=\alpha \underline{E}$ where $\underline{E}$ is the field, and $\alpha$ is the isotropic atomic polarizability, taken from Miller and Savchik [34]. These dipoles were then expressed as induced charges using the mulfit technology, described above $[21,22,30-32]$. These new induced charges were added to the permanent charges to generate a new QM/MM system, and in accordance with previous work [8] this process was iterated four times, bringing the system very close to convergence. Examining the individual point charges, the largest change in the charge on an MM point as a result of the final iteration of the method was of magnitude 0.000011 . In each case, calculations were performed at the B3LYP/6-31G(d) level of theory. Five energy values were calculated, labelled $\mathrm{E}_{1}$ to $\mathrm{E}_{5}$ (all of which are determined at the geometry of the complex). $E_{1}$ was defined as the energy of the monomer in vacuo. $E_{2}$ was defined to be the first SCF energy from the first SCF cycle of a QM/MM run, namely the energy of the 
monomer wavefunction in the presence of the point charges. Thus $\mathrm{E}_{2}-\mathrm{E}_{1}$ gives the energy of the electrostatic interaction between the unperturbed wavefunction and the point charges. $E_{3}$ was defined as the converged SCF energy for the initial QM/MM run, such that $E_{3}-E_{2}$ is equal to the polarization energy of the QM system in response to the MM charges. $\mathrm{E}_{4}$ was defined as the energy of the converged QM/MM run after one iteration of the classical polarization process, while $\mathrm{E}_{5}$ was defined as the energy of the final QM/MM run, after four iterations of the classical polarization process. Hence the total MM polarization energy is derived from $\mathrm{E}_{5}-\mathrm{E}_{3}$. The induced charge polarization energies included the self energy correction [8].

Barrier heights for the reaction were calculated by comparing the energy values at different stages in the QM/MM calculation. For example, the height of the barrier to transition state, incorporating $\mathrm{MM}$ polarization, was given by subtracting the value of $\mathrm{E}_{5}$ from the QM/MM run on the reactant from the value of $\mathrm{E}_{5}$ from the $\mathrm{QM} / \mathrm{MM}$ run on the transition state. The energy values $E_{1}$ to $E_{5}$ are tabulated in supporting information. However, the key focus of this article is not so much the magnitude of the energy barriers but the extent to which they are effected by $M M$ polarization, which is essentially given by $E_{4}-E_{3}$ (one iteration) and $E_{5}-$ $\mathrm{E}_{3}$ (4 iterations).

\section{Results and Discussion}


The MM polarisation energies for the reactant in aqueous solution as a function of the cutoff are shown in Figure 1. The MM energy of polarisation with a $10 \AA$ cutoff was calculated to be $-70.9 \mathrm{kcal} \mathrm{mol}^{-1}$. The curve of the graph appears to increase asymptotically. Using the assumption that the polarisation energy in a shell of distance $r$ from the ligand is proportional $\underline{\text { to } \mathrm{r}^{-3} \text { (see supporting information), an estimate for the asymptote was calculated at }-76.2 \mathrm{kcal}}$ mol $^{-1}$. The figure suggests that MM polarisation is primarily a short-range effect, with $77 \%$ of the MM polarisation energy occurring on molecules within $5 \AA$ of the ligand, and $93 \%$ of the MM polarisation energy being captured by a simulation with a cutoff of $10 \AA$. This high percentage justifies the use of the $10 \AA$ cutoff. Where different structures for the enzyme at different stages of the reaction are compared, the differences are likely to be close to the site of ligand binding. Thus, the effect on the energy of MM polarization of residues more than $10 \AA$ from the binding site is likely not only to be small, but very similar between the structures. Because of this, the resultant error in the energy of transition state stabilisation caused by neglecting MM polarization of residues more than $10 \AA$ from the ligand is likely to be negligible. 
Table 1. Polarization energy values for the enzyme and aqueous systems, at different stages in the reaction pathway. The final column gives the MM polarization energy as a percentage of sum of the electrostatic and polarization energies.

\begin{tabular}{l|ccc}
\hline & $\begin{array}{c}\left.\text { Energy (kcal mol } \mathbf{~}^{-1}\right) \\
\text { QM polarization }\end{array}$ & MM polarization & \% MM \\
& $\mathrm{E}_{3}-\mathrm{E}_{2}$ & $\mathrm{E}_{5}-\mathrm{E}_{3}$ & polarization \\
\hline Enzyme system & -15.4 & -94.9 & 14.9 \\
Reactant & -14.4 & -94.9 & 17.4 \\
Transition state & -14.1 & -91.2 & 16.2 \\
Product & & & \\
& & & \\
Aqueous system & -10.2 & -70.9 & 18.1 \\
Reactant & -9.4 & -72.3 & 19.1 \\
Transition state & -9.4 & -72.8 & 19.1 \\
Product & & & \\
\hline
\end{tabular}

Table 1 shows QM and MM polarization energies for the reactants, transition structure and products in both the enzyme and water systems. The total MM polarization energy is relatively large, at about $17 \pm 2 \%$ of the total electrostatic and polarization interaction, which places this towards the upper end of the expected percentage value [32]. This high percentage is to be expected as the chorismate and prephanate are both highly charged and so will exhert a large electric field. The Arg counterions will also exert a large field on their neighbours within the enzyme. Because the numerical MM polarization energy values are indeed large, MM polarization clearly has the potential to influence the rate and mechanism of enzyme catalysed reactions determined using QM/MM methods. Examination of the induced charges 
1

2

3

4

5

6

7

8

9

10

11

12

13

14

15

16

17

18

19

20

21

in the MM system from the enzyme system showed that the largest changes occur on residues and water molecules close to the carboxylate groups in the ligand, e.g. Arg 90.

Figure 2 shows a graphical representation of the changes in MM charges for the three systems. Comparison of the figures for reactant, transition state and product systems show that the changes in the MM charges are roughly constant across the three systems. Residues and water molecules containing atoms that have large induced charges (i.e. greater than 0.1 ) are listed in supporting information.

Table 1 shows that the MM polarization of the enzyme in the reactant and transition structure configurations is also very similar (the MM polarization energies do not differ by more than $4 \%$ ). The effect of this in this case, is that inclusion of MM polarization has a small effect on the energy barrier for the conversion of chorismate to prephenate since polarization increases the stability of the ligand in both the reactant and transition structure configurations by a similar amount of the energy. A similar conclusion was reached by Szefczyk et al. on the basis of quantum mechanical energy decomposition calculations on a limited number of active site residues [35]. Thus the increase in the barrier from reactant to transition state when MM polarization is incorporated into the model is only $0.1 \mathrm{kcal} \mathrm{mol}^{-1}$ (once the full QM energies have been included, see supporting information).

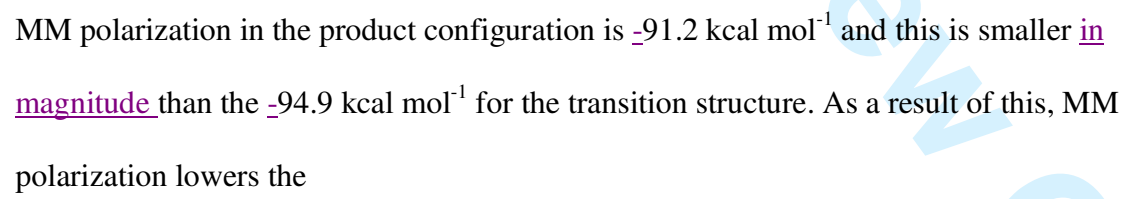



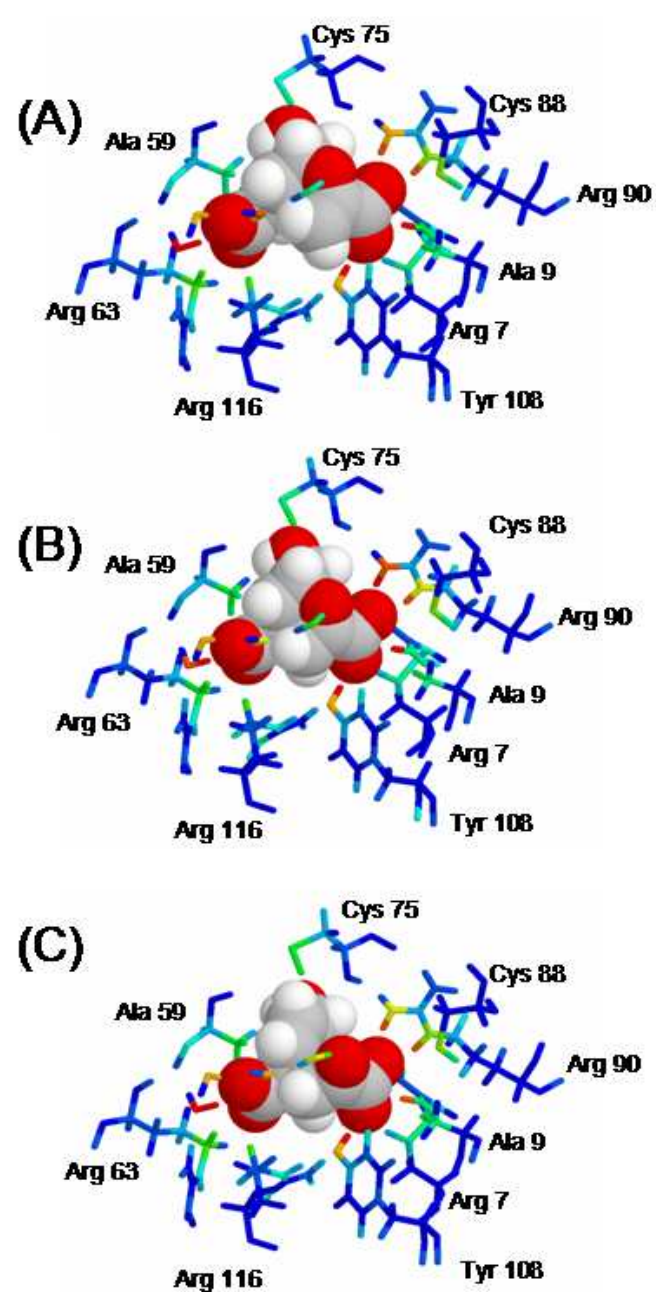

Figure 2. A graphical representation of the induced charges on the enzyme and key water molecules in (A) the reactant configuration, (B) the transition structure and (C) the product configuration. Atoms shown in red have the largest induced charges; atoms shown in blue have the smallest induced charges. The magnitude of the induced charge is equal to the change made to the original charge in the model. The chorismate ligand is shown in a spacefilling representation in CPK colours. In each of the 3 cases, the induced charges are shown mapped onto the transition state configuration. barrier for the reverse reaction by $7.5 \mathrm{kcal} \mathrm{mol}^{-1}$ (once the full QM energies have been included) 
Here we have demonstrated the feasibility of including classical polarization of MM charges [8] in QM/MM studies of enzyme mechanisms. When considering the enzyme alone, our calculations suggest that MM polarization does not affect the barrier height to the transition state in the enzyme system. An implication of the lower predicted contribution of MM polarization to transition state stabilization in the enzyme compared to water is that if MM polarization plays a lower role than expected, then reactive conformation selection may play a higher role than expected. However, a definitive answer on the impact of MM polarization on the chorismate mutase reaction would require a more careful treatment of the enzyme system, possibly by investigating multiple pathways [16].

\section{Acknowledgements}

We wish to acknowledge Medivir(UK) and the BBSRC for support. 
References

1. L.Pauling, Chem. Eng. News 24, 1375 (1946).

2. L.Gan, M. R. Seyedsayamdost, S. Shuto, A. Matsuda, G. A. Petsko, and L. Hedstrom, Biochemistry 42, 857 (2003).

3. M.J.Costanzo, S. C. Yabut, H. R. Almond, Jr., P. Andrade-Gordon, T. W. Corcoran, L. De Garavilla, J. A. Kauffman, W. M. Abraham, R. Recacha, D. Chattopadhyay, and B. E. Maryanoff, J Med. Chem. 46, 3865 (2003).

4. S.P.Dharmasena, D. S. Wimalasena, and K. Wimalasena, Biochemistry 41, 12414 (2002).

5. G.A.Kicska, P. C. Tyler, G. B. Evans, R. H. Furneaux, V. L. Schramm, and K. Kim, J Biol. Chem. 277, 3226 (2002).

6. I.Basu, G. Cordovano, I. Das, T. J. Belbin, C. Guha, and V. L. Schramm, J Biol. Chem. 282, 21477 (2007).

7. R.E.Rigsby, C. L. Rife, K. L. Fillgrove, M. E. Newcomer, and R. N. Armstrong, Biochemistry 43, 13666 (2004).

8. C.J.Illingworth, S. R. Gooding, P. J. Winn, G. A. Jones, G. G. Ferenczy, and C. A. Reynolds, J. Phys. Chem. A 110, 6487 (2006).

9. L.Pauling, Nature 161, 707 (1948).

10. S.Marti, J. Andres, V. Moliner, E. Silla, I. Tunon, J. Bertran, and M. J. Field, J. Amer. Chem. Soc. 123, 1709 (2001).

11. P.D.Lyne, A. J. Mulholland, and W. G. Richards, J. Amer. Chem. Soc. 117, 11345 (1995).

12. K.E.Ranaghan, L. Ridder, B. Szefczyk, W. A. Sokalski, J. C. Hermann, and A. J. Mulholland, Mol. Phys. 101, 2695 (2003).

13. S.Hur, T. C. Bruice, Proc. Natl. Acad. Sci. U. S. A 100, 12015 (2003).

14. S.Hur, T. C. Bruice, J. Amer. Chem. Soc. 125, 10540 (2003).

15. S.Hur, T. C. Bruice, J. Amer. Chem. Soc. 125, 5964 (2003).

16. F.Claeyssens, K. E. Ranaghan, F. R. Manby, J. N. Harvey, and A. J. Mulholland, Chem Commun. 5068 (2005).

17. K.E.Ranaghan, L. Ridder, B. Szefczyk, W. A. Sokalski, J. C. Hermann, and A. J. Mulholland, Org. Biomol. Chem 2, 968 (2004).

18. F.Claeyssens, J. N. Harvey, F. R. Manby, R. A. Mata, A. J. Mulholland, K. E. Ranaghan, M. Schutz, S. Thiel, W. Thiel, and H. J. Werner, Angew. Chem. Int. Ed. 45, 6856 (2006). 
19. P.Kast, M. AsifUllah, and D. Hilvert, Tetrahedron Letters 37, 2691 (1996).

20. M.Barbany, H. Gutierrez-de-Teran, F. Sanz, J. Villa-Freixa, and A. Warshel, Chembiochem 4, 277 (2003).

21. S.R.Gooding, P. J. Winn, R. I. Maurer, G. G. Ferenczy, J. R. Miller, J. E. Harris, D. V. Griffiths, and C. A. Reynolds, J. Comput. Chem. 21, 478 (2000).

22. P.J.Winn, G. G. Ferenczy, and C. A. Reynolds, J. Comput. Chem. 20, 704 (1999).

23. J.H.Wu, P. J. Winn, G. G. Ferenczy, and C. A. Reynolds, Int. J. Quant. Chem. 73, 229 (1999).

24. S.Marti, J. Andres, V. Moliner, E. Silla, I. Tunon, and J. Bertran, J. Phy. Chem. B 104, 11308 (2000).

25. Y.Duan, C. Wu, S. Chowdhury, M. C. Lee, G. M. Xiong, W. Zhang, R. Yang, P. Cieplak, R. Luo, T. Lee, J. Caldwell, J. M. Wang, and P. Kollman, J. Comput. Chem. 24, 1999 (2003).

26. Frisch MJ, Trucks GW, Shlegel HB, Scuseria GE, Robb MA et al. (2004) Gaussian 03, Revision C.02, version Wallingford CT:

27. A.D.Becke, J. Chem. Phys. 98, 5648 (1993).

28. W.J.Hehre, R. Ditchfield, and J. A. Pople, J. Chem. Phys. 56, 2257 (1972).

Deleted: $-\&$

29. A.J.Stone, J. Chem. Theory Comput. 1, 1128 (2005).

30. G.G.Ferenczy, J. Comput. Chem. 12, 913 (1991).

31. G.G.Ferenczy, P. J. Winn, and C. A. Reynolds, J. Phys. Chem. A 101, 5446 (1997).

32. P.J.Winn, G. G. Ferenczy, and C. A. Reynolds, J. Phys. Chem. A 101, 5437 (1997).

33. Stone AJ, Dullweber A, Engkvist O, Fraschini E, Modges MP et al. (2002) Orient: a program for studying interactions between molecules, version 4.5 , version University of Cambridge, Enquiries to AJ Stone, ajs1@ cam.ac.uk. 2006.:

34. K.J.Miller, J. A. Savchik, J. Amer. Chem. Soc. 101, 7206 (1979).

35. B.Szefczyk, F. Claeyssens, A. J. Mulholland, and W. A. Sokalski, Int. J. Quant, Chem. 107, 2274 (2007). 
Supporting information for CM paper

\section{The effect of MM polarization on the QM/MM transition state stabilization: application to chorismate mutase}

\section{Christopher J. R. Illingworth ${ }^{1}$, Kevin E. Parkes ${ }^{2}$, Christopher R. SnelI ${ }^{2}$, S. Marti ${ }^{3}$, Vincent Moliner ${ }^{3}$, Christopher A. Reynolds ${ }^{1, *}$}

${ }^{1}$ Department of Biological Sciences, University of Essex, Wivenhoe Park, Colchester, CO4 3SQ, United Kingdom, ${ }^{2}$ Medivir UK Ltd., Chesterford Research Park, Little Chesterford, Essex CB10 1XL, United Kingdom ${ }^{3}$ Departament de Ciències Experimentals, Universitat Jaume I, Box 224, Castellón, Spain,.

Table S1 Energy values (E1 to E5) for the different systems tested. The measured data gives the raw energy values, from the QM/MM run. The 'point charges' terms are the energy of the MM point charges, considered in isolation. These are subtracted from the measured energy values to give the corrected energy terms, which give the energy of the QM region. All values are in Hartrees.

\begin{tabular}{|c|c|c|c|c|c|c|}
\hline Enzyme system & & 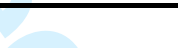 & & & $\ldots$ & Formatted Table \\
\hline \multicolumn{7}{|l|}{ Reactant } \\
\hline & E1 & E2 & $\mathbf{E 3}$ & E4 & $\mathbf{E 5}$ & \\
\hline Measured & -837.116367 & -890.763672 & -890.788264 & -891.809700 & -891.858188 & \\
\hline Point charges & & -52.561503 & -52.561503 & -53.288037 & -53.328917 & \\
\hline \multirow[t]{2}{*}{ Corrected } & -837.116367 & -838.202169 & -838.226761 & -838.521662 & -838.529271 & \\
\hline & & & & & $+\cdots$ & Formatted Table \\
\hline \multicolumn{7}{|l|}{ Transition state } \\
\hline & E1 & E2 & E3 & E4 & E5 & \\
\hline Measured & -837.077742 & -891.310861 & -891.333852 & -892.422144 & -892.462504 & \\
\hline Point charges & & -53.291836 & -53.291836 & -54.085155 & -54.118100 & \\
\hline \multirow{2}{*}{ Corrected } & -837.077742 & -838.019025 & -838.042016 & -838.336988 & -838.344403 & \\
\hline & & & & & $+\cdots$ & Formatted Table \\
\hline \multicolumn{7}{|l|}{ Product } \\
\hline & E1 & E2 & E3 & $\mathbf{E} 4$ & E5 & \\
\hline Measured & -837.154240 & -890.767666 & -890.790086 & -891.782741 & -891.813676 & \\
\hline Point charges & & -52.538422 & -52.538422 & -53.246409 & $-53.27 ¥ 563$ & Formatted Table \\
\hline Corrected & -837.154240 & -838.229243 & -838.251663 & -838.536332 & -838.542113 & \\
\hline \multicolumn{7}{|l|}{ Water system } \\
\hline \multicolumn{7}{|l|}{ Reactant } \\
\hline & E1 & E2 & E3 & E4 & E5 & \\
\hline Measured & -837.118475 & -934.850326 & -934.866611 & -937.768985 & -937.836082 & \\
\hline Point charges & & -97.237494 & -97.237494 & -99.919034 & -99.981136 & \\
\hline Corrected & -837.118475 & -837.612832 & -837.629117 & -837.849952 & -837.854946 & \\
\hline & & & & & $+\cdots$ & Formatted Table \\
\hline
\end{tabular}




\begin{tabular}{|c|c|c|c|c|c|c|}
\hline \multicolumn{7}{|l|}{ Transition state } \\
\hline & E1 & E2 & $\mathbf{E 3}$ & E4 & E5 & \\
\hline Measured & -837.067469 & -934.813571 & -934.828516 & -937.601088 & -937.667587 & \\
\hline Point charges & & -97.274160 & -97.274160 & -99.821504 & -99.883029 & \\
\hline \multirow[t]{2}{*}{ Corrected } & -837.067469 & -837.539411 & -837.554356 & -837.779584 & -837.784558 & \\
\hline & & & & & $4--$ & Formatted Table \\
\hline \multicolumn{7}{|l|}{ Product } \\
\hline & E1 & E2 & $\mathbf{E 3}$ & E4 & E5 & \\
\hline Measured & -837.154179 & -934.850215 & -934.865217 & -937.656686 & -937.725032 & \\
\hline Point charges & & -97.218959 & -97.218959 & -99.783683 & -99.846802 & Formatted Table \\
\hline Corrected & -837.154179 & -837.631257 & -837.646258 & -837.873003 & -837.878230 & \\
\hline
\end{tabular}

Table S2 Largest changes in point charges in MM region of reactant system

\begin{tabular}{ccccc}
\hline Residue & Atom & $\begin{array}{c}\text { Initial } \\
\text { charge }\end{array}$ & $\begin{array}{c}\text { Final } \\
\text { charge }\end{array}$ & Change \\
\hline Tyr 108 & HH & 0.358 & 0.555 & 0.197 \\
TIP3 86 & H & 0.372 & 0.567 & 0.195 \\
Arg 7 & 2HH2 & 0.421 & 0.609 & 0.188 \\
TIP3 86 & O & -0.744 & -0.931 & -0.187 \\
Arg 90 & 2HH1 & 0.421 & 0.599 & 0.179 \\
Arg 90 & HE & 0.323 & 0.499 & 0.176 \\
HOH 105 & O & -0.744 & -0.918 & -0.174 \\
Tyr 108 & OU & -0.476 & -0.642 & -0.166 \\
HOH 105 & H & 0.372 & 0.536 & 0.164 \\
Arg 90 & N2 & -0.835 & -0.998 & -0.163 \\
TIP3 70 & $\mathrm{H}$ & 0.372 & 0.531 & 0.159 \\
TIP3 70 & $\mathrm{O}$ & -0.744 & -0.903 & -0.158 \\
HOH 41 & $\mathrm{H}$ & 0.372 & 0.524 & 0.152 \\
HOH 41 & $\mathrm{O}$ & -0.744 & -0.885 & -0.141 \\
Arg 7 & 1HH1 & 0.421 & 0.557 & 0.137 \\
Arg 90 & $\mathrm{NE}$ & -0.511 & -0.638 & -0.127 \\
Cys 88 & $\mathrm{SG}$ & -0.243 & -0.119 & 0.124 \\
Arg 116 & 1HD & 0.058 & 0.170 & 0.112 \\
Arg 63 & 1HD & 0.058 & 0.168 & 0.111 \\
Arg 63 & $\mathrm{CD}$ & 0.101 & -0.008 & -0.109 \\
\hline
\end{tabular}

Table S3 Largest changes in point charges in MM region of transition state system

\begin{tabular}{ccccc}
\hline Residue & Atom & $\begin{array}{c}\text { Initial } \\
\text { charge }\end{array}$ & $\begin{array}{c}\text { Final } \\
\text { charge }\end{array}$ & Change \\
\hline Tyr 108 & HH & 0.358 & 0.552 & 0.193 \\
TIP3 86 & H & 0.372 & 0.561 & 0.189 \\
Arg 90 & $2 \mathrm{HH} 1$ & 0.421 & 0.607 & 0.187 \\
Arg 7 & 2HH2 & 0.421 & 0.603 & 0.183 \\
TIP3 86 & O & -0.744 & -0.922 & -0.178 \\
Arg 90 & HE & 0.323 & 0.499 & 0.176 \\
Arg 90 & N2 & -0.835 & -1.002 & -0.167 \\
Tyr 108 & OU & -0.476 & -0.638 & -0.162
\end{tabular}




\begin{tabular}{ccccc} 
HOH 105 & $\mathrm{H}$ & 0.372 & 0.531 & 0.159 \\
HOH 41 & $\mathrm{H}$ & 0.372 & 0.530 & 0.158 \\
TIP3 70 & $\mathrm{H}$ & 0.372 & 0.525 & 0.152 \\
TIP3 70 & $\mathrm{O}$ & -0.744 & -0.894 & -0.150 \\
HOH 41 & $\mathrm{O}$ & -0.744 & -0.894 & -0.150 \\
HOH 105 & $\mathrm{O}$ & -0.744 & -0.888 & -0.144 \\
ARG7 & 1HH1 & 0.421 & 0.562 & 0.141 \\
ARG90 & NE & -0.511 & -0.643 & -0.131 \\
CYS88 & SG & -0.243 & -0.121 & 0.122 \\
ARG116 & 1HD & 0.058 & 0.160 & 0.102 \\
TIP3 51 & $\mathrm{O}$ & -0.744 & -0.845 & -0.101 \\
ARG63 & 1HD & 0.058 & 0.158 & 0.101 \\
TYR108 & $\mathrm{HH}$ & 0.358 & 0.552 & 0.193 \\
TIP3 86 & $\mathrm{H}$ & 0.372 & 0.561 & 0.189 \\
\hline
\end{tabular}

Table S4 Largest changes in point charges in MM region of product system

\begin{tabular}{ccccc}
\hline Residue & Atom & $\begin{array}{c}\text { Initial } \\
\text { charge }\end{array}$ & $\begin{array}{c}\text { Final } \\
\text { charge }\end{array}$ & Change \\
\hline TIP3 86 & $\mathrm{H}$ & 0.372 & 0.558 & 0.185 \\
TYR108 & $\mathrm{HH}$ & 0.358 & 0.539 & 0.180 \\
TIP3 86 & $\mathrm{O}$ & -0.744 & -0.918 & -0.173 \\
ARG7 & 2HH2 & 0.421 & 0.592 & 0.171 \\
ARG90 & 2HH1 & 0.421 & 0.588 & 0.168 \\
ARG90 & HE & 0.323 & 0.484 & 0.160 \\
HOH 105 & $\mathrm{H}$ & 0.372 & 0.529 & 0.157 \\
TIP3 70 & $\mathrm{H}$ & 0.372 & 0.523 & 0.151 \\
TYR108 & OU & -0.476 & -0.626 & -0.150 \\
HOH 41 & $\mathrm{H}$ & 0.372 & 0.518 & 0.146 \\
TIP3 70 & $\mathrm{O}$ & -0.744 & -0.889 & -0.144 \\
HOH 105 & $\mathrm{O}$ & -0.744 & -0.885 & -0.141 \\
ARG90 & $\mathrm{N} 2$ & -0.835 & -0.972 & -0.138 \\
ARG7 & 1HH1 & 0.421 & 0.556 & 0.136 \\
HOH 41 & $\mathrm{O}$ & -0.744 & -0.880 & -0.136 \\
TIP3 51 & $\mathrm{O}$ & -0.744 & -0.870 & -0.126 \\
CYS88 & SG & -0.243 & -0.124 & 0.119 \\
ARG90 & NE & -0.511 & -0.630 & -0.119 \\
ARG116 & 1HD & 0.058 & 0.158 & 0.100 \\
ARG63 & 1HD & 0.058 & 0.157 & 0.100 \\
\hline
\end{tabular}

\section{Curve estimation}

In the reactant water system, an estimate is given for the total MM polarisation energy, if the reactant was in an infinite amount of water. This is given by the following method:

Suppose that the total magnitude of the MM polarisation energy is equal to some limit, L. Dividing space according to its distance from the ligand into regions of thickness $1 \AA$, and defining the polarisation energy of the waters in the shell of distance a to $a+1 \AA$ from the ligand to be $\mathrm{e}(\mathrm{a})$, we have: 


$$
L=\sum_{a=0}^{\infty} e(a)
$$

If the polarization energy e(a) of each shell is defined primarily in terms of chargedipole interactions, the average strength of an individual interaction will be roughly proportional to $\mathrm{a}^{-4}$, while the volume of the shell is roughly proportional to $\mathrm{a}^{2}$. Thus it roughly holds that

$e(a) \propto a^{-4} * a^{2}=a^{-2}$

If we define

$$
E(r)=\sum_{a=0}^{r-1} e(a)
$$

we can then say that

$$
L=E(r)+\sum_{a=r}^{\infty} e(a)
$$

Given the proportionality relation defined for e(a), it then holds roughly that

$$
\sum_{a=r}^{\infty} e(a) \propto \sum_{a=r}^{\infty} \frac{1}{a^{2}}
$$

Noting that

$$
\frac{1}{a^{2}}-\frac{1}{a(a+1)}=\frac{1}{a^{2}(a+1)}
$$

we then have the result

$$
\sum_{a=r}^{\infty} e(a) \propto \sum_{a=r}^{\infty} \frac{1}{a^{2}}=\sum_{a=r}^{\infty}\left[\frac{1}{a(a+1)}+\frac{1}{a^{2}(a+1)}\right]=\sum_{a=r}^{\infty} \frac{1}{a(a+1)}+\sum_{a=r}^{\infty} \frac{1}{a^{2}(a+1)}
$$

Looking at the first sum, we have

$$
\sum_{a=r}^{\infty} \frac{1}{a(a+1)}=\sum_{a=r}^{\infty}\left[\frac{1}{a}-\frac{1}{a+1}\right]=\frac{1}{r}
$$

since successive terms of the sum cancel out. For the second sum, we have

$$
\sum_{a=r}^{\infty} \frac{1}{a^{2}(a+1)}=\sum_{a=r}^{\infty} \frac{1}{a}\left[\frac{1}{a}-\frac{1}{a+1}\right]<\sum_{a=r}^{\infty} \frac{1}{r}\left[\frac{1}{a}-\frac{1}{a+1}\right]=\frac{1}{r^{2}}
$$

As r increases, this second sum becomes small, so we can say approximately that

$$
\sum_{a=r}^{\infty} e(a) \propto \frac{1}{r}
$$

Hence, for some constant $\mathrm{c}_{1}$, we have the model

$$
L=E(r)+\frac{c_{1}}{r}
$$

If, however, the energy e(a) of each shell is defined primarily in terms of dipoledipole interactions, the average strength of an individual interaction will be roughly proportional to $\mathrm{a}^{-6}$. It would then follow, again roughly, that

Deleted: for some constant $c_{1}$

Formatted: Lowered by $14 \mathrm{pt}$

Deleted: $\sum_{a=r}^{\infty} e(a) \propto \sum_{a=}^{\infty}$

Formatted: Lowered by $14 \mathrm{pt}$

Formatted: Lowered by $15 \mathrm{pt}$

Formatted: Lowered by $14 \mathrm{pt}$

Formatted: Lowered by $14 \mathrm{pt}$

Formatted: Lowered by $14 \mathrm{pt}$

Deleted: and so just above we showed that $\mathrm{e}(\mathrm{a})$ prop to $\mathrm{a}^{-2}$ so why do we have $1 / \mathrm{r}$ here and not $1 / \mathrm{r}^{2} ?$ ?

Formatted: Superscript

Formatted: Superscript

Deleted: for some constant $c_{2}$

$$
\begin{aligned}
& e(a) \propto a^{-6} * a^{2}=a^{-4} \\
& \sum_{a=r}^{\infty} e(a) \propto \frac{1}{r^{3}} \text { and }
\end{aligned}
$$


$L=E(r)+\frac{c_{2}}{r^{3}}$ for some constant $\mathrm{c}_{2}$.

Therefore, suppose that for some constant values $\mathrm{k}$ and $\mathrm{c}$, the amount of polarisation energy in the volume up to $r$ Ångstroms away from the ligand obeys the function

$$
E(r)=L-\frac{c}{r^{k}} \quad \text { Eq.1 }
$$

This would imply that

$$
E(r+1)-E(r)=\left(L-\frac{c}{(r+1)^{k}}\right)-\left(L-\frac{c}{r^{k}}\right)=c\left(\left(\frac{1}{r^{k}}\right)-\left(\frac{1}{(r+1)^{k}}\right)\right) \text { Eq.2 }
$$

By looking at the calculated data, we then attempt to deduce the values of $\mathrm{k}$ and $\mathrm{c}$, in order to create a model for the polarisation energy.

| Taking values of $\mathrm{r}$ from 8 to 11 Ångstroms gives the following observed differences:

Deleted: experimental

Deleted: ……… Page Break

Formatted Table

\begin{tabular}{ccc}
\hline$r$ & $E(r)$ & $E(r)-E(r-1)$ \\
\hline 8 & -67.73682 & -2.571943 \\
9 & -69.48578 & -1.748963 \\
10 & -70.85499 & -1.36921 \\
11 & -71.73236 & -0.877372 \\
\hline
\end{tabular}

These differences can be compared to model difference values computed using different values of $\mathrm{k}$, for example where $\mathrm{k}$ is equal to 1 , as follows:

\begin{tabular}{|ccccc}
\hline$r$ & $E(r)$ & $E(r)-E(r-1)$ & $\begin{array}{c}\text { Predicted } \\
\text { difference }\end{array}$ & $c(r)$ \\
\hline 8 & -67.73682 & -2.571943 & 0.017857143 & -144.0288241 \\
9 & -69.48578 & -1.748963 & 0.013888889 & -125.9253718 \\
10 & -70.85499 & -1.36921 & 0.011111111 & -123.2288624 \\
11 & -71.73236 & -0.877372 & 0.009090909 & -96.51094997 \\
\hline
\end{tabular}

Formatted Table

Formatted Table

Here the predicted difference is equal to $\mathrm{E}(\mathrm{r})-\mathrm{E}(\mathrm{r}-1)$ as given from Eq. 2 above, under the assumption that $\mathrm{c}=1$, while $\mathrm{c}(\mathrm{r})$ is the observed difference divided by the predicted difference at each $\mathrm{r}$, that is, the value of $\mathrm{c}$ in Eq.2 needed to give a correct answer at that $r$.

By repeating this with different values of $k$, different sets of values of $c(r)$ can similarly be computed. The goodness of fit of the model is indicated by the consistency of the values $\mathrm{c}(\mathrm{r})$ at each value of $\mathrm{r}-$ if $\mathrm{c}(\mathrm{r})$ was constant that would indicate a perfect fit to the model, while a large variation in $\mathrm{c}(\mathrm{r})$ would indicate a poor model fit.

The consistency of the value of $\mathrm{c}(\mathrm{r})$ was measured at different values of $\mathrm{k}$ by calculating the standard deviation of the $\mathrm{c}(\mathrm{r})$ values divided by the mean of the $\mathrm{c}(\mathrm{r})$ values at that value of $\mathrm{k}$. For simplicity, $\mathrm{k}$ was assumed to be an integer. This gave the following results: 
As can be seen from the table, $\mathrm{k}=2$ gives the best fit for this model. Given this result, the constant $\mathrm{c}$ was defined as the mean of the values $\mathrm{c}(8)$ to $\mathrm{c}(11)$ already calculated, giving the model:

$$
\begin{aligned}
& E(r+1)-E(r)=-540.1\left(\left(\frac{1}{r^{2}}\right)-\left(\frac{1}{(r+1)^{2}}\right)\right) \\
& E(11)=-71.732
\end{aligned}
$$

The limit of this sequence was calculated computationally up to $r=10000$, giving a limiting value for the energy of $-76.2 \mathrm{kcal} \mathrm{mol}^{-1}$.

This model does not fit directly to either of the two scenarios presented above, but a number of factors need to be taken into account. Firstly, it is primarily a numerical procedure and there is not much data to extrapolate from. Secondly, it ignores higher order terms as they rapidly become small. For example if the energy varied according to $\mathrm{c} 1 / \mathrm{r}+0.3 \mathrm{c} 2 / \mathrm{r} 3$ then at $\mathrm{r}=11 \AA$, the first term is 50 times bigger than the second. It was argued above that the charge - (induced) dipole correction would be proportional to $\mathrm{r}-2$ but this would only be true if the magnitude of the changes in the charges was constant - but this is unlikely to be true given the charged chorismate involved and this decrease in induced charge with distance from the chorismate may explain the preference for $\mathrm{k}=2$ rather than $\mathrm{k}=1$ in our model. 